\title{
Content analysis in negotiation research: A review and guide
}

\author{
KAREN L. HARRIS \\ Western Illinois University, Macomb, Illinois
}

\begin{abstract}
Content analysis, a technique in which inferences are derived from the communication of interacting parties, is not utilized enough in mainstream negotiation research. The purpose of the present article is to outline the benefits and limitations inherent in the content analysis technique, to provide a comprehensive review of content analysis systems that have been used in the past, and to evaluate the existing systems in an effort to guide readers in the decision process. This article aids the potential consumer-any person considering the use of content analysis in negotiation research-in making informed choices regarding this technique. Choice among existing systems should be based upon one's research question and upon accepted standards of quality. A system that is relatively comprehensive, well grounded in theory, and demonstrates acceptable levels of reliability is advocated. Specific recommendations regarding quality systems are provided.
\end{abstract}

Negotiation is pervasive in nearly all forms of human social interaction. Whenever the desires of two or more people are perceived to be mutually exclusive and the players involved choose to develop an agreement to satisfy their needs, a form of negotiation is at work. Negotiation can be applied to all levels of social conflict, ranging from a quarrel between friends or family members to full-scale warfare between nations. As a result, social scientists have long been interested in the processes and outcomes associated with negotiation.

Performance is a major issue for much of the negotiation literature. Optimal performance, in the form of an agreement that objectively maximizes the interests of all parties involved, is regarded as highly desirable. As such, most of the investigation to date has focused upon two forms of dependent measures: economic measures and social-psychological measures (Thompson, 1990). Economic measures focus solely upon outcomes of a negotiation. They do not take into consideration the process by which those outcomes are achieved, and a standard of optimal performance is often used as a comparison by which to judge the effectiveness of a negotiation. Socialpsychological measures focus on both the process and the outcome of negotiation. They are usually in the form of a set of ratings of the outcome, of one's opponent, and of oneself (Thompson \& Hastie, 1990). Social-psychological

This material is based upon work supported by a faculty research grant from the University Research Council at Western Illinois University. The helpful comments from class members of the graduate seminar on conflict resolution held at Western Illinois University-Ronelle Allen, Bobby Bailey, Joan Holgate, Eboni House, and Alan Rhea-are gratefully acknowledged. The author also thanks Nimet Beriker, Laurie Weingart, and an anonymous reviewer for their suggestions, which resulted in a much improved manuscript. Correspondence should be sent to K. L. Harris, Department of Psychology, Western Illinois University, Macomb, IL 61455 (e-mail: karen_harris@ccmail.wiu.edu). measures reflect the subjective judgments and perceptions of the negotiators involved. Both forms of dependent measures are present in most negotiation experimental research performed today. They strongly reflect the dominant paradigm: an emphasis upon outcome, sometimes at the cost of process.

\section{CONTENT ANALYSIS}

Missing from this picture is investigation delving into the content of the verbal communication involved in negotiation. Holsti (1968, p. 596) went so far as to claim that "the study of the processes and content of communication is basic to all social sciences." This argument may appropriately be applied to investigation of the processes underlying a negotiated settlement. Verbal communication is responsible for the successful end to nearly any social conflict. As such, the systematic study of that communication may well be in order. As stated by Cartwright (1953, p. 422),

Social and political conflicts, although often stemming from divergent economic interests and power, cannot be fully understood without studying the words employed in the interaction of conflicting groups, and the process of mediation consists largely in talking things out. The work of the world, and its entertainment, too, is in no small measure mediated by verbal and other symbolic behavior.

The research tool known as content analysis has been applied for several decades to studying topics of interest to social psychologists. Content analysis is "any technique for making inferences by systematically and objectively identifying specified characteristics of messages" (Holsti, 1968, p. 601). Content analysis has many purposes and can take many forms, as dictated by the research question under investigation.

Content analysis is implemented by use of a coding scheme. This coding scheme is designed and guided by 
the primary research questions. Once the coding scheme is in place, verbal units are systematically and objectively classified by trained judges. Occurrences of verbal utterances can then be compared in order to reach some conclusions about the content of subjects' communications. The communications field maintains a set of widely accepted practices in developing and applying coding schemes, some of which are indicated in this review. Readers in need of more detailed explanations of coding protocol are directed to two good sources on the subject: Baxter (1991) and Folger, Hewes, and Poole (1984).

Content analysis is a research tool readily applicable to the communication undertaken by negotiators. Yet the suggestion that this methodological tool be applied in negotiation studies represents a severe departure from the prevailing norm. The application of a relatively complex content coding scheme to the verbal utterances by negotiators is a large and somewhat risky undertaking for any research program. It requires a comprehensive and reliable coding scheme, a means of transcribing verbal information, motivated and trained coders, and lots of time. Likewise, the predominant paradigm emphasizing outcome over process renders content analysis incompatible with negotiation research currently in vogue. Thus, for several practical and logistic reasons, content analysis is not frequently used in mainstream research. Yet the potential benefits of content analysis in the negotiation literature are well worth exploring. Though sparse, research utilizing content analysis does appear to be gaining some momentum in recent years (e.g., Alexander, Schul, \& Babakus, 1991; Galinat \& Muller, 1988; Jones, 1988; McGillicuddy, Welton, \& Pruitt, 1987; Parrott, Greene, \& Parker, 1992; Weingart, Bennett, \& Brett, 1993; Weingart, Thompson, Bazerman, \& Carroll, 1990). Moreover, this pursuit represents a bridging: A methodology, deriving from the field of communication, is applied to an interdisciplinary substantive issue. Increased use of content analysis would conceivably add a new dimension to the understanding of this phenomenon, enabling researchers to observe, record, and analyze the verbal processes taking place between bargainers.

A researcher, or potential consumer, considering the use of content analysis has likely already judged that the "subjects' own language is crucial to the research problem" (Holsti, 1968, p. 603). The potential content analyst should have a research question founded upon the assumption that negotiators' verbal communication reflects behavioral preferences and choices. Verbal messages are assumed to be meaningful representations of the negotiation process. As in any form of research, one's assumptions about human interaction will strongly influence one's choice of method (Duck \& Montgomery, 1991). In this instance, the nature of the research problem, coupled with assumptions about the crucial role of communication in negotiation, naturally leads the researcher to become a consumer of the content analysis technique.

The purpose of this article is threefold: (1) to outline the benefits and limitations inherent in the proposed technique, (2) to provide a comprehensive review of content analysis systems that have been used in the past, and (3) to evaluate the existing systems in an effort to guide potential consumers in the decision process. An attempt has been made to provide the most comprehensive and exhaustive list of existing coding systems available to date. In order to be included on this list, however, a system had to meet a few criteria. First, only those content analysis systems devised with the purpose of coding bargaining simulations conducted in the laboratory, rather than negotiations taking place in naturalistic settings, have been reviewed in this article. The vast majority of coding systems were developed for simulated bargaining. Systems constructed specifically for naturalistic settings (Donohue, Diez, \& Hamilton, 1984; Osterberg, 1950; Rackham, 1972) were not included for review.

Second, only those systems that were fully revealed in the text of the relevant article were included in the following review. A system, for instance, by McGillicuddy et al. (1987), mentioned 26 categories of negotiator behavior but revealed the identity of only those categories that showed significant results. For this reason, the McGillicuddy et al. system and others like it were not discussed.

Third, several general-purpose coding systems have been developed. The present article includes only those systems that were constructed for the express purpose of coding negotiation activity. Thus, systems such as Bales's (1950) interaction process analysis, which was developed to code small group interaction, were eliminated. For this same reason, Stiles's (1978) verbal response modes were not discussed. Jones's (1988) mediation process analysis (MPA) was a system developed for discourse occurring in divorce mediation cases; it codifies communication of not only the negotiators of such a case but also that of the mediators and additional parties (e.g., attorneys for the negotiators). Thus, the MPA was not considered in this article. Several analysts (McGrath \& Julian, 1963; Morley \& Stephenson, 1977; Putnam \& Jones, $1982 \mathrm{~b}$ ) strongly argue that general-purpose systems fail to capture elements integral to the bargaining context, such as the use of strategies and concessions, rendering them less than ideal for such investigations.

Finally, only content analysis schemes are reviewed, in contrast to interaction analysis schemes. Content analysis schemes, which represent the majority of systems developed for application to negotiation, are designed to examine each verbal utterance independently of one another. Interaction analysis schemes (e.g., Donohue, 1981) are designed to investigate the interrelationships among utterances, and they fall beyond the scope of this review.

\section{WHY CONTENT ANALYSIS?}

Care must be taken before embarking upon content analysis. Large investments of time and resources require a preconception of what such an analysis entails. With this in mind, a summary of benefits and limitations is provided for the reader and potential consumer of the content analysis technique. 


\section{Benefits}

The results derived from content analysis, when it is put to use, complement the information stemming from studies performed in a more traditional manner. Outcome the objective value of the negotiators' settlementis the heart of traditional economic measures. Bargainers are expected to attempt to maximize personal and/or mutual gain. A variety of measures, such as concession rate and joint profit, may be formulated to reflect bargaining effectiveness. Yet the outcome of a negotiation is very different from the process used in reaching that outcome. Economic measures fail to reflect the interpersonal dynamics existing between negotiators as they develop a workable solution to their differences. Economic measures are highly restrictive in that they do not provide a basis for analyzing the behaviors, emotions, motives, and tactics used to derive the final product. The content analysis' greatest strength is its ability to provide exactly this kind of information.

The results of content analysis may also complement those of traditional social-psychological measures. Socialpsychological measures are intended to capture the negotiation process to an extent. Numerous self-reports of the context, of one's own motives and strategies, and of one's perceptions of the motives and strategies of the opponent may be utilized. But such measures are restricted to the negotiator's perceptions of these elements. As several advocates of the cognitive approach to understanding negotiation have expressed, people are not always rational in the negotiation process (Bazerman \& Neale, 1983; Thompson \& Hastie, 1990). Due to a lack of information necessary to objectively analyze the situation, people tend to be biased in their judgments regarding negotiation. Thus, social-psychological measures are reflections of the inaccurate views possessed by the parties involved. Information derived from social-psychological measures is useful to a point, in that it helps to explain the sometimes irrational choices made by bargainers. But a party extraneous to the talks, such as the experimenter, may be in a better position to analyze the motives, tactics, and emotions of both negotiators. The experimenter has complete information about the negotiation task available, has no immediate personal stake in the negotiation outcome, and is more likely to be objective in assessing the process. When content analysis is used in conjunction with other, more popular, techniques within a study, the results may be accepted with greater confidence.

Furthermore, when asked about impressions of a foregone negotiation, bargainers are required to provide selfreports in retrospect. Any time data are gathered in this manner, memory shortcomings and cognitive biases may influence the results (Thompson \& Hastie, 1990). Content analysis provides a means of gathering process data without the inherent dangers of such lapses; the verbal information is at the coder's fingertips, and reflection upon past events is not necessary.

A large portion of past laboratory research in the substantive areas of competition and negotiation is notable for its limited verbal interaction. In fact, the use of com- puters in providing stimuli and gathering responses is currently popular. Computer use in this context certainly has its benefits, but it does tend to inhibit or completely eliminate the need for negotiators to exchange information face to face. The use of content analysis encourages a free exchange of communication. In fact, the primary requirement for the use of content analysis is free verbal interaction. Content analysis may function as a catalyst in increasing the realism of laboratory experiments.

Finally, content analysis may aid in answering the question, "Do the results of simulated negotiations in laboratory settings really provide insight into people's conduct in real-world negotiation?" Negotiation simulations have long been used in laboratories, taking for granted their potential for generalizability of results. Content analysis may serve as a tool to compare events taking place during laboratory simulations and real-world negotiations and, in so doing, provide the researcher with at least some limited confidence in the external validity of experimental results. In a study, for instance, by Beriker and Druckman (1996), the process and outcome of a simulated historic peace negotiation were compared with those of the actual negotiations. Such a comparison was made possible by the use of a content analysis scheme. Considerable correspondence between the processes taking place in the simulated and in the actual talks led these researchers to conclude that simulations do indeed serve as a viable method for contributing to knowledge about negotiation.

\section{Limitations}

A purpose of this article was to outline the benefits of content analysis in negotiation and to advocate wider use. However, limitations to this or any research technique are inevitable. For instance, the results of a content analysis are never pure or completely objective by any means. Subjective judgment plays a major role at two steps in the content analysis. The first point at which the experimenter has a subjective hand is in the development of the coding scheme. Any coding scheme is largely shaped by the experimenter's theoretical perspective on the research questions under investigation. The manner in which the research problem is formulated will guide the experimenter in choosing a set of classifications. Thus, the coding scheme reflects the personal priorities and biases of the experimenter; in a sense, the individual researcher's approach to the problem serves as a constraint upon the nature of the coding system (Duck \& Montgomery, 1991). The degree of subjectivity, however, may be minimized by an effort to develop a system consonant with the current and well-established body of theoretical knowledge.

Second, the implementation of the coding scheme is influenced by subjective judgment. Coders are selected and trained by the experimenter. Once they become familiar with the system, these coders are explicitly asked to use their own personal judgments in classifying verbal units. Thus, at this step of the coding process, inference and subjectivity on the part of the experimenter as well as 
that of the coders play a role in the results of a content analysis. This problem, too, can be minimized by the use of well-defined, distinct categories, thus reducing the coder's task from a judgmental one to mere clerical work.

The argument has been made that use of the content analysis technique lacks a holistic view of the negotiation process (Donohue et al., 1984). That is, the objective in most traditional coding schemes is to develop frequency counts of discrete negotiator behaviors. This provides information about how often a set of behaviors is used, establishing patterns of dominant behavior. This approach, however, overlooks the issue of the timing and sequencing of these behaviors. Analysts (e.g., Druckman, 1991; Putnam \& Jones, 1982a) argue that when tactics are used is as important as how often they are used.

In response to this particular criticism, a few researchers have used methodological and statistical techniques in order to adapt. Whereas most research in the area of negotiation focuses almost exclusively upon antecedents and outcomes of bargaining and depicts the process of bargaining as some kind of mystery, content analysts have the unique opportunity to examine the microprocesses involved in constructing a mutually acceptable agreement. As mentioned previously, a separate class of systems, known as interaction analysis schemes, are available to explore the interrelationships of verbal communication. Also to aid in this endeavor, recent work (e.g., Putnam \& Jones, 1982a; Weingart et al., 1993) has made use of lag sequential analysis to identify systematic patterns of behavior. By using sequential analysis (Sackett, 1979), questions regarding the timing and sequencing of communication behaviors may be explored. In fact, a major advantage of content analysis is that it allows the potential of comparative work, including comparison of behaviors at similar or different stages of negotiation (Druckman, 1991). Examples include comparing negotiation behavior at different points in time within a single negotiation, comparing different discussions that take place during a single time period within a single negotiation, and comparing parallel processes that take place across different negotiations.

Finally, the associated costs must be taken into account when considering content analysis. As previously stated, it requires a great deal of time and effort to implement a content analysis. The decision to do so should not be taken lightly. A careful weighing of the potential costs versus potential benefits for a particular project is in order.

\section{A REVIEW OF EXISTING CONTENT ANALYSIS SYSTEMS}

\section{Early Single-Purpose Attempts}

Initial attempts to use content analysis in the study of negotiation process met with some success. Two such attempts were identified in the literature. These two systems share the unfortunate fate of being put to use a very limited number of times. Such one-shot attempts are fairly characteristic of the initial attempts to codify negotiation communication. These early coding schemes also tend to be a compilation of strategies loosely tied to- gether as a result of a disparate set of empirical findings. These earlier systems fail to be firmly based in a coherent theoretical perspective. These early coding schemes, however, are notable in that they helped to spark subsequent rigorous efforts to establish content analysis systems for the primary purpose of investigating verbal interaction in negotiation situations.

McGrath and Julian (1963), for instance, coded interactions among subjects in a simulated negotiation. All utterances were coded as positive, negative, or neutral affect. Likewise, those same verbal statements were coded as content structuring (attempts to structure the content of the group activity) or as procedural structuring (attempts to establish operating procedures). Each statement was also coded with regard to who initiated it and to whom it was directed.

Zechmeister and Druckman (1973) double-coded their verbal data in a similar manner. Utterances were distinguished as either cognitive arguments (descriptive statements expressing no preference) or value arguments (statements of preference). They were then coded as statements revealing similarities between opponents, as statements revealing differences between opponents, or as neutral statements.

\section{Variations of Pruitt and Lewis (1975)}

Pruitt and Lewis (1975) reported a coding scheme developed as a result of various strategies found to be effective (or ineffective) in developing integrative agreements (agreements maximizing both parties' joint gain). Several categories were employed, including several specific forms of information exchange (e.g., asking for truthful information, giving truthful information, giving false information), calling for concession, using pressure tactics (i.e., threats, positional commitments, and statements bringing in extraneous issues), proposing a general approach that may be used to produce agreement, showing concern, and proposing coordination.

Several variations of the Pruitt and Lewis scheme were later developed, using haphazard methods to pull together successful categories previously used with new categories tailored to the particular concepts under investigation (Ben-Yoav \& Pruitt, 1984; Kimmel, Pruitt, Magenau, Konar-Goldband, \& Carnevale, 1980; Lewis \& Fry, 1977; Schulz \& Pruitt, 1978). Not one of these efforts can be traced to a single unifying theoretical framework.

\section{Bargaining Process Analysis}

Bargaining process analysis (BPA) is a content analysis system developed and refined by Walcott, Hopmann, and their colleagues. BPA was a system that was originally developed from a particular theoretical orientation and later implemented empirically to provide evidence of its reliability and utility.

BPA is one of the few content analysis systems that has been systematically modified through repeated use. The origin of BPA may be traced to Hopmann (1972) in an analysis of historic arms control negotiations. This system was later collapsed into two broad categories for subse- 
quent use by Hopmann and King (1976) and Druckman and Harris (1990). They utilized a very simple twobehavior system, identifying hard-line bargaining (e.g., commitments, threats, and accusations) and soft-line bargaining (e.g., accommodations, promises, praise) as the categories of interest. Another shortened version of BPA was utilized by Putnam and Jones (1982a) in their investigation of reciprocity in negotiation. Using factor analysis to identify dimensions within BPA, they chose to analyze their results using three forms of negotiator behavior: defensive moves (e.g., retractions, accommodations, promises, commitments, and self-supporting arguments), offensive moves (e.g., threats, rejections, demands, attacking arguments, requesting information, clarification, and providing reaction), and integrative strategies (e.g., supporting messages, problem solving, procedural statements, and acceptances).

The complete BPA system (Walcott \& Hopmann, 1978) consisted of four major categories of potential behavior: substantive behavior, strategic behavior, task behavior, and affective behavior. The first two categories, substantive and strategic behaviors, were drawn from Schelling's (1960) conceptual system of negotiator behavior. Strategic behavior portrayed in conflict situations was the central theme in Schelling's book. Such behavior was defined as the more "rational, conscious, artful kind of behavior" (Schelling, 1960, p. 3). It comprises actions intended to maneuver one's opponent toward conceding, often in the form of covert pressure. Drawing upon this source, BPA subcategories of strategic behavior included commitments, threats, and promises.

Substantive behaviors were defined as statements directly involved in the process of negotiation. Subcategories were in the form of proposals, accommodations, and retractions. Whereas strategic behaviors are designed to influence the opponent's behavior, substantive behaviors are more self-directed, not as cold and calculating.

The last two primary categories, task and affective behaviors, were drawn from Bales's (1950) interaction process analysis, a system designed to assess communication in small groups. Interaction process analysis originated from Bales's extensive theoretical work on group roles and has enjoyed a great deal of attention in the group literature. Bales's perception of emergent roles taken on by group members was patterned after the traditional division of labor in the household: one family member (the husband) was the doer, the accomplisher; thus, "task behavior" is displayed likewise by one group member. The other family member (the wife) was the nurturer, the caregiver; thus, "affective behavior" is displayed in a similar manner by one group member.

Task behaviors were defined in the BPA as all statements directed at carrying out the task of negotiation but did not directly involve the substance of negotiation. Subcategories included agreements, disagreements, questions, and answers. Affective behaviors were statements reflecting emotions and comprised the subcategories of positive affect and negative affect. A fifth category, "procedural behaviors," served as a residual category for state- ments that carry the negotiations along but do not easily fit into any of the other categories.

\section{Conference Process Analysis}

Yet another coding scheme developed to test propositions of negotiating behavior was the conference process analysis (CPA) developed by Morley and Stephenson (1977) and adapted from the work of Longabaugh (1963). Longabaugh conceptualized social interaction as an exchange of resources and, thus, sharply distinguished between the way information is exchanged and the function of that information. The CPA maintained that conceptualization by judging verbal utterances along two dimensions: (1) "mode" of information exchange, or how a statement is made (offer, accept, reject, seek), and (2) "resource," or what sort of information is exchanged (statements of procedure, offers, limits, positive consequences of proposed outcomes, negative consequences of proposed outcomes, other statements about outcomes, positive acknowledgments, negative acknowledgments, and information).

The CPA also required a third judgment along the dimension of "referent," or the subject of the message (none, self, another party, opponent, one's own constituents, opponent's constituents, both persons, both parties' constituents). This third dimension distinguishes CPA from the framework set forth by Longabaugh (1963). Morley and Stephenson's (1977) CPA added the "referent" dimension to

indicate who is being explicitly described in the information being exchanged and, furthermore, to make a distinction between Personal and Party considerations which is of considerable theoretical interest in the study of negotiation groups. (p. 193)

That is, for their purposes, Morley and Stephenson believed that the frequency of "I" or self-directed statements, relative to the frequency of other-directed statements, was worthy of investigation. This third dimension was inspired by the work of Grace and Tandy (1957), who found that a greater proportion of other-directed statements indicated more hostile relations among parties.

\section{Variations of the Bonoma and Rosenberg System}

A set of categories was proposed by Bonoma and Rosenberg (1975). Although their original system was designed to reflect any form of social interaction, it was derived from a theoretical orientation assuming that social interaction always takes place under conditions of conflict. Thus, it has been adapted by others as a scheme for investigating communication patterns in bargaining situations.

Upon extending the Bonoma and Rosenberg system to negotiation, Angelmar and Stern (1978) constructed the following set of categories: promises, threats, warnings, recommendations, rewards, punishments, positive and negative normative appeals, commitments, self-disclosures, questions, and commands. These authors drew parallels between elements of their system and the conceptual model of negotiation behavior by Walton and McKersie 
(1965), thus attempting to establish the system's theoretical relevance.

In a similar adaptation, Galinat and Muller (1988) devised a system consisting of the following: attempted antagonistic influence (i.e., warnings, threats, punishments, and negative normative appeals), attempted cooperative influence (i.e., recommendations, promises, and rewards), strategic questions, justifications (i.e., positive normative appeals and commitments), self-disclosure, concessions, concession refusal, and "other." Although there is not perfect correspondence between this system and the earlier system by Angelmar and Stern (1978), even a cursory examination reveals a great deal of overlap and similarity.

\section{Weingart et al. Systems}

Yet another set of coding schemes was developed to suit the individual propositions of studies performed by Weingart and her colleagues (Weingart et al., 1993; Weingart, Hyder, \& Prietula, in press; Weingart et al., 1990). Weingart et al. (1990) and Weingart et al. (1993) explained that the coding schemes originated from reviews of existing categorization schemes and empirical negotiation research. Though the authors did not explicitly label the categories as such, most of them fall under the broader division of cooperative or competitive behaviors. Their 1990 system comprised nine major categories. These categories were listed as single-issue offers, multiple-issue offers, suggesting a tradeoff, asking for information, showing concern for the other party, providing information, negative reaction, positive reaction, and threats/warnings.

Weingart et al.'s 1993 system displayed some elements in common and comprised single-issue offers, multi-issue offers, providing information about preference for level within issue, providing information about priorities across issues, substantiation of position, understanding of other parties' level preference, understanding of other parties' priorities, understanding of other parties' positions, delayed reciprocity suggested, mutuality of concerns, procedural comments, questions, and agreement/disagreement.

More recently, Weingart et al. (in press) have made an effort to streamline their coding scheme and have addressed to a greater extent questions about the theoretical underpinnings of the scheme. Their latest study provided yet another variation, which first outlined several distributive bargaining components: single-issue offers, providing information about preferences within an issue, substantiation, questions about preferences within an issue, questions about substantiation, and procedural comments about addressing one issue at a time and about compromising. Clear distinction was made between these and integrative bargaining behaviors: multiple-issue offers, providing information about priorities among issues, questions about priorities among issues, and procedural comments about issue tradeoffs and about reciprocating concessions. Two additional categories were positive reactions and miscellaneous comments. The structure of this scheme underscores the dichotomy of distributive bargaining (behaviors that seek to maximize one's personal profit) versus integrative bargaining (behaviors that seek to maximize both parties' joint profit), and it reflects the most contemporary understanding of negotiation behavior.

\section{COMPARING AND EVALUATING THE EXISTING SYSTEMS}

A question plaguing system developers is the feasibility of constructing a standard set of categories. Standardization is desirable largely to provide a means of comparing results across different empirical studies and to increase accuracy (reliability) of a system used by multiple researchers. Coding systems are typically developed through a trial-and-error process, in which tentative categories are constructed and then modified in light of the data on hand. Construction and implementation of a coding scheme require a large investment of time. The diverse groups of researchers, each aiming for the same goal, may best be served by a unified coding system that has been deemed to have adequate reliability and to be sufficiently complex to provide meaningful conclusions. In an overview of the role of communication in bargaining, Putnam and Jones (1982b) argued that standardization of category systems is imperative in building a dependable body of knowledge.

Unfortunately, this is not the current state of affairs. More typical is the use of systems developed ad hoc, specifically for the investigation at hand. In striving to be original, researchers tend to be very reluctant to adopt coding schemes developed by others (Druckman, 1991).

Yet, regardless of how strong a case is made in favor of standardization of negotiation coding schemes, one must be aware of the implications. Holsti (1968) claimed that the goal of standardization is a difficult one to achieve considering the disparity of purposes linked to different studies. In at least some cases, researchers will be forced to develop a coding scheme to suit the purposes of their own particular investigations because no existing schemes are currently available to capture the variations of interest. And no matter how comprehensive a scheme one is able to create, that scheme, if applied universally to all negotiations studies, would still limit the interpretation of the data because it necessarily reflects the (biased) viewpoint of its creator. It may be most prudent to conclude that there is room both for standardization and for innovative approaches.

With these warnings in mind, a primary purpose of this article is still to aid in the promotion of a standard coding scheme for studies of the bargaining process, because few previous efforts have been made in this direction. It is a contention that common elements among the existing set of systems can be identified and utilized in constructing a single coherent coding scheme, which can be used repeatedly for content analysis. These commonalities reflect the perspective of many negotiation analysts: Elements of content, style, and affect appear in any type of negotiation. Coding scheme developers are placing their efforts in specifying the details about the particular types of content, style, and affect that are of greatest import in understanding negotiation interaction. The ultimate objective is a system that strikes a balance between 
reliability, such that results can be verified by independent observers, and meaningfulness, such that the final set of categories is large enough to accurately capture the complexities of negotiation communication (Holsti, 1968). This system must be firmly rooted in theoretical grounding (Putnam \& Jones, 1982b). A well-developed standardized system does not necessarily restrict the user; the system that is sufficiently complex may be adapted to the needs of the particular researcher through cumulation or expansion of existing categories. Repeated use of a limited number of coding systems affords analysts the opportunity to make comparisons among results of disparate research programs, thereby moving one step closer to developing an overall picture of the interplay between verbal communication and negotiation outcomes.

\section{COMPARING EXISTING SYSTEMS}

In gathering all of the existing negotiation coding schemes in one place, it becomes a relatively easy task to compare those schemes. Although the terminology and degree of distinction differs among schemes, three elements have been identified as common to all or most of the existing coding schemes: elements of content, style, and affect.

Elements of content include all behavioral categories directly related to the task of bargaining. Any positive behavior directed at moving the negotiations along a path to integrating positions and eventual resolution would fall under this heading. Likewise, any negative behavior directed at slowing down or stalling negotiations, or any form of distributive bargaining, would be considered an element of content.

Most of the existing schemes also contain elements of style. These elements are behaviors directed at the process of bargaining. They involve how negotiations are carried out. Specific examples of stylistic behaviors include setting an agenda, establishing order of speaking, and determining the number of issues to be negotiated simultaneously.

Affective elements are also a common theme throughout several of the currently existing coding schemes. Both positive and negative expressions of emotion would serve as examples of affective elements.

Comparing the existing systems on these three dimensions would allow the consumer to view the elements in common, as well as the gaps in each of the schemes. Such a comparison enables one to better understand how standardization of systems might occur. To aid in this endeavor, specific comparisons among categories from the different systems are provided in Table 1. Each category is classified as an element of content, style, or affect. The content category is further broken down into three subclasses for ease in comparison: positive behaviors, negative behaviors, and unspecified.

\section{Evaluating Existing Systems}

In guiding the potential consumer of existing coding systems, it is also necessary to evaluate existing systems with respect to a set of widely accepted criteria for assessing the quality of a coding scheme. Most analysts agree that such a system must meet the criteria of validity, empirical reliability, and theoretical relevance.

It is difficult to ascertain the degree of effort placed in establishing validity of any of the schemes under review since such analyses, if performed, were not reported in any detail. The norm among system developers appears to be a general acceptance of a particular system if it appears valid "in the eyes of the beholder." In other words, most developers seem to agree implicitly that a content validity analysis is sufficient in judging the validity of a set of categories. Holsti (1968) confirmed that this is a reasonable course of action if the purpose of the research is purely descriptive. Authorities on the topic of interaction analysis commonly refer to this as representational validity, which means the degree to which a set of categories is meaningful to those who would ordinarily engage in the interaction of interest (in this case, negotiation).

What does this mean for the potential consumer of established coding schemes? How can the consumer judge whether the coding scheme of interest has adequate representational validity? There are no fixed rules available to answer these questions. But the literature that directly addresses this issue seems to indicate that it is acceptable to make an informal, subjective validity judgment of the system under consideration. One common method of obtaining representational validity is to review the scheme with people deemed to be "experts" in negotiation. Unfortunately, the consumer may not be informed within the text of the reporting article about whether or not this operation took place at the time the system was developed.

The majority of effort among system developers seems to have been directed at establishing degree of empirical reliability in a new coding scheme. The goal in operationalizing a coding scheme is to produce a set of categories that emit results that are easily replicated by independent observers. Furthermore, a system developer strives to construct a scheme that is reliable across projects or even across programs conducted by different researchers. To reach this goal, one must have a limited set of clearly defined, clearly distinguishable categories. Evidence of reliability typically is provided in the form of interrater reliability coefficients, produced by correlating the judgments of independent observers. One such widely used measure of agreement is Cohen's (1960) kappa, which corrects for chance agreement. Comparisons of reliability across different projects are sometimes reported by researchers using a scheme repeatedly. Greatest confidence can be placed in schemes that maintain high levels of reliability across different judges and across different research projects. The major disadvantage to producing a system with high reliability is the danger that such a system can be so oversimplified as to distort the concept under study.

Walcott and Hopmann's (1978) BPA is one system that has been rigorously tested in this manner. The transcripts from numerous runs of a simulated arms control negotiation served as material for testing the reliability of the BPA coding scheme (Walcott \& Hopmann, 1978). Interrater reliabilities were computed for each of the 13 sub- 
Table 1

A Comparison of Coding Schemes: Elements of Content, Style, and Affect

\begin{tabular}{|c|c|c|c|c|c|}
\hline & \multicolumn{3}{|c|}{ Content } & \multirow[b]{2}{*}{ Style } & \multirow[b]{2}{*}{ Affect } \\
\hline & Positive Behaviors & Negative Behaviors & Unspecified & & \\
\hline $\begin{array}{l}\text { McGrath \& } \\
\text { Julian (1963) }\end{array}$ & & & content structuring & procedural structuring & $\begin{array}{l}\text { positive, negative, } \\
\text { neutral }\end{array}$ \\
\hline $\begin{array}{l}\text { Zechmeister } \\
\text { \& Druckman (1973) }\end{array}$ & statement/similarity & $\begin{array}{l}\text { cognitive arguments, } \\
\text { value arguments, } \\
\text { statement/differences }\end{array}$ & neutral statement & none & none \\
\hline Pruitt \& Lewis (1975) & $\begin{array}{l}\text { information exchange, } \\
\text { call/concession, } \\
\text { coordination }\end{array}$ & pressure tactics & & $\begin{array}{l}\text { proposing a general } \\
\text { approach }\end{array}$ & showing concern \\
\hline $\begin{array}{l}\text { Walcott \& } \\
\text { Hopmann (1978) }\end{array}$ & $\begin{array}{l}\text { proposals, } \\
\text { accommodations, } \\
\text { promises, agreements, } \\
\text { questions, answers }\end{array}$ & $\begin{array}{l}\text { retractions, } \\
\text { commitments, threats, } \\
\text { disagreements }\end{array}$ & & procedural behaviors & positive, negative \\
\hline $\begin{array}{l}\text { Morley \& } \\
\text { Stephenson (1977) }\end{array}$ & $\begin{array}{l}\text { offers, positive } \\
\text { consequences, } \\
\text { information }\end{array}$ & $\begin{array}{l}\text { limits, negative } \\
\text { consequences }\end{array}$ & statement/outcomes & $\begin{array}{l}\text { statements of } \\
\text { procedure }\end{array}$ & $\begin{array}{l}\text { positive acknowledg- } \\
\text { ments, negative } \\
\text { acknowledgments }\end{array}$ \\
\hline $\begin{array}{l}\text { Galinat \& } \\
\quad \text { Muller (1988) }\end{array}$ & $\begin{array}{l}\text { recommendations, } \\
\text { promises, rewards, } \\
\text { questions, positive } \\
\text { norms, self-disclosure, } \\
\text { concessions }\end{array}$ & $\begin{array}{l}\text { warnings, threats, } \\
\text { punishments, negative } \\
\text { norms, commitments, } \\
\text { concession refusal }\end{array}$ & & none & none \\
\hline Weingart et al. (in press) & $\begin{array}{l}\text { multi-issue offer, } \\
\text { information-issue } \\
\text { priority, question- } \\
\text { issue priority }\end{array}$ & $\begin{array}{l}\text { single-issue offer, } \\
\text { information within } \\
\text { issue, questions } \\
\text { within issue, question- } \\
\text { substantiation }\end{array}$ & & $\begin{array}{l}\text { procedural comments } \\
\text { about addressing } \\
\text { one issue at a time, } \\
\text { procedural comments } \\
\text { about compromising, } \\
\text { procedural comments } \\
\text { about issue tradeoffs, } \\
\text { procedural comments } \\
\text { about reciprocating } \\
\text { concessions }\end{array}$ & positive reactions \\
\hline
\end{tabular}

Note-To avoid redundancy, a few systems were omitted from this table due to their high degree of similarity to others that were included (e.g., Angelmar \& Stern, 1978; Druckman \& Harris, 1990; Hopmann \& King, 1976; Putnam \& Jones, 1982a; Weingart et al., 1993; Weingart et al., 1990).

categories composing the scheme. These reliability correlations ranged between .659 and .977 . The average of these 13 correlations was .922 , which is an impressive value considering the level of complexity in the BPA system. This scheme (or a reduced version of it) has been used repeatedly in other projects, and it consistently provides adequate reliability among independent observers trained in the BPA system (Druckman \& Harris, 1990; Hopmann \& King, 1976; Hopmann \& Walcott, 1976; Parrott et al., 1992; Putnam \& Jones, 1982a).

Morley and Stephenson (1977) also conducted extensive research in establishing the operationalizations and reliability of their CPA system. In a book introducing the system, its category definitions, and empirical work testing the limits of CPA, these authors reported reliability values ranging from .645 to .916 . These results, too, were derived from multiple experiments and multiple observers.

The system of Bonoma and Rosenberg (1975) has not been tested to as great an extent, relative to BPA and CPA. The Angelmar and Stern (1978) and the Galinat and Muller (1988) variations are the only known replications of the original Bonoma and Rosenberg system. The set of categories by Weingart et al. (1993; Weingart et al., in press; Weingart et al., 1990), although not in existence long enough to be adequately judged as to its degree of consistency across research projects, shows promise in its regularity of appearance in the current literature.
Much effort has also been directed at establishing the degree of theoretical relevance of a new coding scheme. The means of establishing such relevance is linking the system's categories to current theoretical knowledge about negotiation behavior. Putnam and Jones (1982b) strongly argued that a category system must reflect conceptual principles established in the negotiation literature. In order to meet the relevance criterion, a content analysis system should contain a relatively large number of categories, which make rather fine discriminations among negotiator behaviors. This system should be adequately comprehensive to cover nearly all forms of behavior that may possibly take place in a negotiation situation.

Unfortunately, such a comprehensive system lowers reliability results due to increased confusion between categories. Thus, in developing and applying a content analysis system, one must be aware of the classic dilemma: A coding scheme may be so complex it becomes unwieldy, or it may be so simple that it becomes meaningless. The ideal system strikes a reasonable balance between complexity (to maximize theoretical relevance and usefulness) and simplicity (to maximize reliability). This set of categories should directly originate from a wellestablished body of theoretical knowledge. Reports of utility (a system's ability to produce meaningful results) derived from several different research projects also aids in establishing theoretical relevance of a coding scheme. 
But what does it mean to align a scheme with key theoretical principles? The potential consumer of a particular content analysis scheme must begin by familiarizing oneself with the origins of that scheme, carefully considering the sequence of development; a coherent theory should precede the construction of a scheme's categories. The theory identifies the important questions and issues to be addressed by research. The theory will serve to highlight those facets of negotiation deemed to be valuable and worthy of investigation. The coding scheme derived directly from that theory will then serve as a tool to help address the issues of concern. If code development occurs in this manner, there will then exist a strong interdependence between the theoretical principles and the method of choice (in this case, content analysis; see Duck \& Montgomery, 1991).

Walcott and Hopmann's (1978) BPA probably comes closest to fulfilling the ideals of theoretical relevance. As previously noted, more programmatic research has been conducted on the BPA than on any other system like it. Reports of meaningful conclusions using the categories of BPA testify to the usefulness of the system. Likewise, BPA categories originated directly from the widely accepted sources of Bales (1950) and Schelling (1960).

Morley and Stephenson's (1977) CPA also approaches this ideal since it originates directly from the theoretical viewpoint of Longabaugh (1963). As previously noted, empirical work testing the limits of CPA has been encouraging; several studies testing different research questions have derived meaningful statements by using CPA. Yet, judging from the limited number of authors and years of those studies, CPA does not appear to have gained as wide an appeal as does BPA. I suspect that CPA has not caught the attention of a general audience, in part, due to the idiosyncrasies of the scheme. For instance, it makes a fine distinction between "mode" and "resource" dimensions. Most analysts seem content to concentrate their efforts on delineating only resources, or the forms of information exchanged (e.g., statements of procedure, offers, information); CPA makes the theoretical distinction between the form of information and mode, or how that information is exchanged (i.e., whether it is conveyed as an offer, acceptance, rejection, or a "seeking"). Perhaps this difference is of less theoretical value to readers than it was to its authors. Likewise, readers may vary in their reactions regarding the importance of specifying the statement's "referent," or the target of the message. Morley and Stephenson admitted that a large amount of time is consumed in coding transcripts using their threedimensional scheme. They stated, for example, that a $35-$ min transcript often takes a full day to code, and that is the pace of a highly trained coder. For these reasons, CPA is not readily adaptable to the needs of a general audience.

The systems by Angelmar and Stern (1978) and by Galinat and Muller (1988) provided less evidence of theoretical relevance. Both do originate from the same source: the conceptual schema by Bonoma and Rosenberg (1975). This schema, however, was originally designed to apply to social interaction in general and therefore does not nec- essarily generate coding schemes strongly tied to negotiation behavior. Angelmar and Stern did make a post hoc effort to relate their category scheme to the bargaining model of Walton and McKersie (1965). On the basis of that analysis, they concluded that the criterion of theoretical relevance was satisfied. The Weingart et al. (in press) system, more current than any other, may reflect the most accurate view of contemporary research on negotiation, particularly in its delineation of distributiveintegrative behaviors. The other systems under review (i.e., McGrath \& Julian, 1963; Pruitt \& Lewis, 1975; Zechmeister \& Druckman, 1973) provided cursory evidence of ties to theoretical knowledge.

The original intent of this article was to highlight the characteristics of each system and to leave it up to the reader to make a personal judgment regarding appropriateness. It was not the mission of this author to advocate one system over another, nor did I wish to add to the confusion by developing yet another system. However, in reflecting upon the information reviewed within these pages, two systems emerge as clearly superior in meeting the criteria set forth. Walcott and Hopmann's (1978) BPA and Morley and Stephenson's (1977) CPA have both been cited as meeting the standards of validity, reliability, and theoretical relevance. In comparing the two, BPA appears to be applicable to a wider array of theoretical questions and easier to use. I would also add that a relatively new system on the scene, the Weingart et al. (in press) coding scheme, shows a great deal of promise; its only drawback is that it has not yet had the chance to develop a "reputation" through repeated use.

\section{CONCLUSION}

The present article is offered as a testimony to the advantages of content analysis in advancing the understanding of the negotiation process. Highlights of such advantages include the ability to study the microprocesses of bargaining communication, a potential to trace the changes and phases taking place over the course of a bargaining session (not ordinarily identifiable using traditional measures), and the ability to compare results of different studies by using a standardized system. The costs and time needed for content analysis do make it prohibitive to some, given the constraints associated with conducting research. Yet the potential gains from such analysis are worth exploring.

Once the decision to use content analysis has been made, the researcher is then faced with a myriad of choices among existing systems, or perhaps devising an original system. Standardization of coding schemes has been strongly encouraged throughout, and this review serves to achieve that goal. The present article attempts to provide the most inclusive review to date of content analysis systems for bargaining. Existing systems have been described and assessed in an effort to provide the reader with a practical guide in selecting one most appropriate. Choice among existing systems should be based upon one's research question and upon accepted standards of 
quality. A system that is relatively comprehensive, well grounded in theory, and that demonstrates acceptable levels of reliability is advocated.

\section{REFERENCES}

Alexander, J. J., Schul, P. L., \& Babakus, E. (1991). Analyzing interpersonal communications in industrial marketing negotiations. Journal of the Academy of Marketing Science, 19, 129-139.

ANGElmar, R., \& STERN, L. W. (1978). Development of a content analytic system for analysis of bargaining communication in marketing. Journal of Marketing Research, 15, 93-102.

BALES, R. F. (1950). Interaction process analysis. Cambridge, MA: Addison Wesley.

BAXTER, L. (1991). Content analysis. In B. M. Montgomery \& S. Duck (Eds.), Studying interpersonal interaction (pp. 239-254). New York: Guilford.

Bazerman, M. H., \& NeALE, M. A. (1983). Heuristics in negotiation: Limitations to effective dispute resolution. In M. H. Bazerman \& R. J. Lewicki (Eds.), Negotiating in organizations (pp. 51-67). Beverly Hills, CA: Sage.

Ben-YoAv, O., \& PruitT, D. G. (1984). Accountability to constituents: A two-edged sword. Organizational Behavior \& Human Performance, 34, 283-295.

BERIKER, N., \& DruCKMAN, D. (1996). Simulating the Lausanne peace negotiations, 1922-23: Power asymmetries in bargaining. Manuscript submitted for publication.

BONOMA, T. V., \& ROSENBERG, H. (1975). Theory-based content analysis: A social influence perspective for evaluating group process. Chicago: Institute for Juvenile Research.

CARTwright, D. P. (1953). Analysis of qualitative material. In L. Festinger \& D. Katz (Eds.), Research methods in the behavioral sciences (pp. 421-470). New York: Holt, Rinehart \& Winston.

COHEN, J. (1960). A coefficient of agreement for nominal scales. Educational \& Psychological Measurement, 20, 37-46.

Donohue, W. A. (1981). Development of a model of rule use in negotiation interaction. Communication Monographs, 48, 106-120.

Donohue, W. A., Diez, M. E., \& Hamilton, M. (1984). Coding naturalistic negotiation interaction. Human Communication Research, $10,403-425$.

DruckMAN, D. (1991). Content analysis. In V. A. Kremenyuk (Ed.), International negotiation (pp. 244-263). San Francisco: Jossey-Bass.

DruCKMAN, D., \& HaRRIS, R. (1990). Alternative models of responsiveness in international negotiation. Journal of Conflict Resolution, 34, 234-251.

Duck, S., \& Montgomery, B. M. (1991). The interdependence among interaction substance, theory, and methods. In B. M. Montgomery \& S. Duck (Eds.), Studying interpersonal interaction (pp. 3-15). New York: Guilford.

Folger, J. P., Hewes, D. E., \& Poole, M. S. (1984). Coding social interaction. In B. Dervin \& M. Voigt (Eds.), Progress in communication sciences (pp. 115-161). Norwood, NJ: Ablex.

Galinat, W. H., \& Muller, G. F. (1988). Verbal responses to different bargaining strategies: A content analysis of real-life buyer-seller interaction. Journal of Applied Social Psychology, 18, 160-178.

GraCE, H. A., \& TANDY, M. J. (1957). Delegate communication as an index of group tension. Journal of Social Psychology, 45, 93-97.

Holsti, O. (1968). Content analysis. In G. Lindzey \& E. Aronson (Eds.), Handbook of social psychology (Vol. 2, pp. 596-692). Reading, MA: Addison-Wesley.

HopmanN, P. T. (1972). Internal and external influences on bargaining in arms control negotiations: The partial test-ban. In B. M. Russett (Ed.), Peace, war, and numbers (pp. 213-237). Beverly Hills, CA: Sage.

HopmanN, P. T., \& KING, T. (1976). Interactions and perceptions in the test ban negotiations. International Studies Quarterly, 20, 105-142.

HopmanN, P. T., \& WALCOTT, C. (1976). The impact of international conflict and detente on bargaining in arms control negotiations: An experimental analysis. International Interactions, 2, 189-206.

JoNES, T. S. (1988). Phase structures in agreement and no-agreement mediation. Communication Research, 15, 470-495.
Kimmel, M. J., Pruitt, D. G., Magenau, J. M., Konar-Goldband, E. \& CARNEVALE, P. J. (1980). Effects of trust, aspiration, and gender on negotiation tactics. Journal of Personality \& Social Psychology, 38, 9-22.

LEWIS, S. A., \& FRY, W. R. (1977). Effects of visual access and orientation on the discovery of integrative bargaining alternatives. Organizational Behavior \& Human Performance, 20, 75-92.

LONGABAUGH, R. (1963). A category system for coding interpersonal behavior as social exchange. Sociometry, 26, 319-344.

McGillicuddy, N. B., Welton, G. L., \& Pruitt, D. G. (1987). Thirdparty intervention: A field experiment comparing three different models. Journal of Personality \& Social Psychology, 53, 104-112.

McGrath, J. E., \& Julian, J. W. (1963). Interaction process and task outcome in experimentally-created negotiation groups. Journal of Psychological Studies, 14, 117-138.

MoRLEy, I., \& STEPHENSON, G. (1977). The social psychology of bargaining. London: Allen \& Unwin.

OsterberG, W. H. (1950). A method for the study of bargaining conferences. Personnel Psychology, 3, 169-178.

Parrott, R., Greene, K., \& Parker, R. (1992). Negotiating child health care routines during pediatrician-parent conversations. Journal of Language \& Social Psychology, 11, 35-45.

PRUITT, D. G., \& LEWIS, S. A. (1975). Development of integrative solutions in bilateral negotiations. Journal of Personality \& Social Psychology, 31, 621-633.

PUTNAM, L. L., \& JonES, T. S. (1982a). Reciprocity in negotiations: An analysis of bargaining interaction. Communication Monographs, 49, 171-191.

Putnam, L. L., \& Jones, T. S. (1982b). The role of communication in bargaining. Human Communication Research, 8, 262-280.

RACKHAM, N. (1972). Developing negotiation skills. Industrial \& Commercial Training, 4, 266-275.

SACKETT, G. P. (1979). The lag sequential analysis of contingency and cyclicity in behavioral interaction research. In J. D. Osofosky (Ed.), Handbook of infant development (pp. 623-649). New York: Wiley.

SChelling, T. C. (1960). The strategy of conflict. Cambridge, MA: Harvard University Press.

Schulz, J. W., \& PruitT, D. G. (1978). The effects of mutual concern on joint welfare. Journal of Experimental Social Psychology, 14, $480-492$.

STILES, W. B. (1978). Verbal response modes and dimension of interpersonal roles: A method of discourse analysis. Journal of Personality \& Social Psychology, 36, 693-703.

ThOMPSON, L. (1990). Negotiation behavior and outcomes: Empirical evidence and theoretical issues. Psychological Bulletin, 108, 515-532.

ThOMPSON, L., \& HAstiE, R. (1990). Judgment tasks and biases in negotiations. In B. H. Sheppard, M. H. Bazerman, \& R. J. Lewicki (Eds.), Research in negotiation in organizations (Vol. 2, pp. 31-54). Greenwich, CT: JAI.

Walcott, C., \& Hopmann, P. T. (1978). Interaction analysis and bargaining behavior. In R. T. Golembiewski (Ed.), The small group in political science: The last two decades of development (pp. 251-261). Athens: University of Georgia Press.

WALTON, R. E., \& MCKERSIE, R. B. (1965). A behavioral theory of labor negotiations. New York: McGraw-Hill.

WeInGART, L. R., BENNETt, R. J., \& BRETT, J. M. (1993). The impact of consideration of issues and motivational orientation on group negotiation process and outcome. Journal of Applied Psychology, 78, 504-517.

Weingart, L. R., Hyder, E. B., \& Prietula, M. J. (in press). Knowledge matters: The effect of tactical descriptions on negotiation behavior and outcome. Journal of Personality \& Social Psychology.

Weingart, L. R., Thompson, L. L., Bazerman, M. H., \& Carroll, J. S. (1990). Tactical behavior and negotiation outcomes. International Journal of Conflict Management, 1, 7-31.

ZeChMEISTER, K., \& DRUCKMAN, D. (1973). Determinants of resolving a conflict of interest. Journal of Conflict Resolution, 17, 63-88.

(Manuscript received March 9, 1995; revision accepted for publication June 8, 1995.) 